\title{
The Effects of Cognitive Stress on Asthma Exacerbations among University Students
}

\author{
Jacquelyn Paquet, BScN, BSc Psychology, Dennell Mah§, BA, \\ Nicholas Coupland ${ }^{\star}, \mathrm{MB} . \mathrm{ChB}, \mathrm{MRCPsych}(\mathrm{UK})$, Harissios Vliagoftis§, \\ MD, FRCPC, Dilini Vethanayagam§, MD, FRCPC
}

§Pulmonary Research Group, Faculty of Medicine \& Dentistry, University of Alberta, Edmonton, Alberta

*Department of Psychiatry, Faculty of Medicine and Dentistry, University of Alberta, Edmonton, Alberta Corresponding author: dilini@ualberta.ca

\section{ABSTRACT}

Introduction: Many asthmatics complain of worsening respiratory symptoms during periods of stress. This study evaluated the relationship among asthma symptoms, lung physiology, inflammatory parameters and perceived cognitive stress and quality of life in healthy adult students. This relationship was assessed at two time points: a time of normal activity and at a time of cognitive stress during academic examinations.

Methods: Subjects attended the University of Alberta Hospital for a screening visit, which included a clinical exam, spirometry, methacholine challenge, allergen skin tests to assess atopy status and Mini International Neuropsychiatric Interview (MINI). Eligible subjects returned for a low stress visit (LSV) at least 14 days prior to an exam and a high stress visit (HSV) within 24 hours of an exam. Spirometry, and methacholine challenge were performed during both LSV and HSV along with the collection of urine (tested for cortisol), and the administration of 4 questionnaires to assess perceived stress and quality of life.

Results: Subjects showed no significant change in psychosocial or quality of life questionnaires between LSV and HSV. No significant change was noted in lung function or urine cortisol. There was an unexpected high rate of pre-existing psychiatric comorbidities in this population (based on the MINI screen failure rate).

Conclusion: We did not find a significant change in quality of life, psychosocial wellbeing or pulmonary function or inflammation, measured by urine cortisol, during a high stress period. The high rate of comorbidities would be important to consider as part of evaluation used in clinical asthma studies in the future.

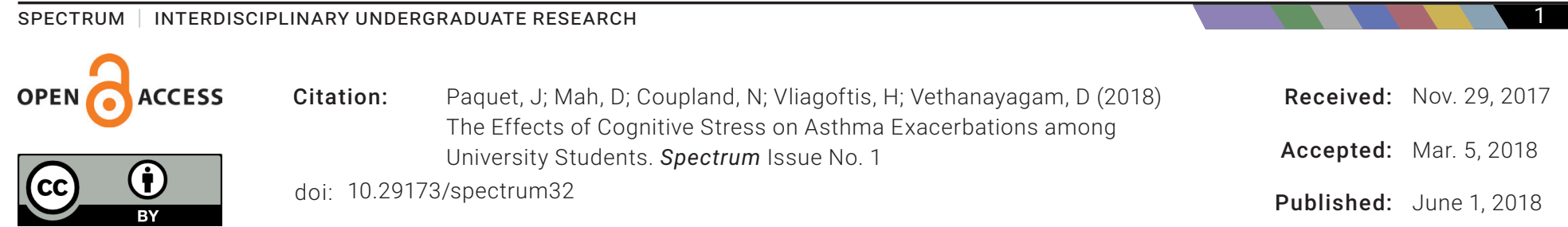




\section{Introduction}

Asthma is a chronic inflammatory disorder of the airways characterized by sudden or persistent symptoms of shortness of breath, chest tightness, wheezing, sputum production, and cough. It is associated with variable airflow limitation and varying degrees of airway hyper-responsiveness to endogenous and exogenous stimuli (Becker et al., 2005; Global Initiative for Asthma, 2016). Asthma is the most common chronic disease of childhood and affects over $8 \%$ of Canadians over the age of twelve (Global Initiative for Asthma, 2016; Statistics Canada, 2017).

Many factors affect disease activity and severity of symptoms, including exposure to allergens, upper and lower airway infections, air pollution, and psychological/ cognitive stress (Christensen et al., 2008). The association of asthma symptoms with stress has been recognized as early as the $12^{\text {th }}$ century (Rosner, 1981); Sir William Osler similarly referred to asthma as "a neurotic affliction" (Osler, 1892). Stress was first described by Hans Selye as the common denominator of all the adaptive reactions in the body (Selye, 1970). Stress can be viewed as a process that accentuates the airway inflammatory response to environmental triggers and, in doing so, increases the frequency, duration, and severity of asthma patients' symptoms (Chen \& Miller, 2007). It is the maladaptive response to stress, which Selye named "distress", that is considered to be detrimental for human homeostasis and for diseases such as asthma (Selye, 1970).

Psychological morbidity has been linked to asthma mortality (Strunk et al., 1985; Sears et al., 1986) and underlying psychological distress (depression and anxiety) (Wright et al., 1998). Depression and asthma have a bidirectional relationship, with depression increasing the chance of asthma exacerbations and asthma increasing the chance of depressive symptomatology (Lu et al., 2014; Trueba et al., 2016). Between 20-35\% of asthmatics experience asthma exacerbations during periods of stress (Isenberg et al., 1992). The National Institutes of Health commissioned a workshop to promote a better understanding of this relationship (Busse et al., 1995); however, little has been done to evaluate the mechanism of these interactions (Smyth et al., 1999; Davis et al., 2002). Some asthmatics experience a reduction in lung function with stress; however, these results are not consistent (Lehrer et al., 1993). A survey of over 3,000 adults in the United States showed increased prevalence of panic attacks in those with obstructive lung disease (Goodwin, \& Pine, 2002). Similarly, depression and anxiety are over-represented in children (Vila et al., 1999; Sundbom et al., 2016) and adults (Sundbom et al., 2016; Krommydas et al., 2004; Harrison, 1998) with asthma. Stress also has many forms: panic disorders and depression can lead to shortness of breath, which appears to be unresponsive to bronchodilators or traditional eosinophil based anti-inflammatory therapy (i.e. psychogenic dyspnea). Moreover, perceived stress depends on one's beliefs and values, which can negatively affect the physiological reaction to stress through cortisol release (Lu et al., 2014; Trueba et al., 2016). Psychosocial stress may further affect environmental triggers to asthma leading to exacerbations and negative asthma outcomes (Dunton et al., 2016). Increased psychological stress among asthmatics has been shown to worsen asthma control, increase medical service use and increased medication requirements (Sunbom et al., 2016). Such stress has also been found to worsen morbidity and demonstrate pulmonary physiological changes, requiring more medications and follow up to manage symptoms exacerbations and functioning (Lu et al., 2014; Dunton et al., 2016). There is evidence for alterations to the immune system with stress (Black, 2002; Sundbom et al., 2016), and demonstrated airway structure and function impairment with long-term stress (Rod et al., 2012). Psychological stress can be due to conditions such as relationship issues, financial difficulties, workrelated stress, or cognitive stress such as during 
examinations. The impact of a condition on a person involves assessment of symptoms, airway inflammation, and effect on day-to-day activities. The World Health Organization's definition of health encompasses this view as "a state of complete physical, mental, and social well-being - not merely the absence of disease or infirmity" (World Health Organization, 2018). Among those with asthma that have a comorbid psychiatric pathology, there is a reduced quality of life as measured by standardized testing (Sundbom et al., 2016).

Assessment of airway inflammation is a more sensitive measure of disease control than symptoms and lung function alone, and a measurable inflammatory response is present in atopic asthmatics despite clinical remission (Van Den Toorn et al., 2001). Atopy is a genetic condition of increased immunological response with underlying medical conditions including allergic rhinitis (hay fever), asthma and atopic dermatitis (eczema) (American Academy of Allergy Asthma \& Immunology, 2018). Recent work utilizing the model of allergen challenge in mild asthmatics has shown changes in serum inflammatory markers during periods of stress, and increased airway inflammation after allergen challenge during high stress periods (Liu et al., 2002).

This pilot study attempted to assess the relationship between cognitive stress and asthma symptoms, physiology (airway narrowing and forced expiratory volume), urine cortisol a marker of inflammation, and quality of life with both general and disease specific validated instruments. We postulated that $\mathrm{FEV}_{1}$ and $\mathrm{PC}_{20}$ would decrease with increased stress. We expected that physiologic changes and quality of life measures would correlate with increased cognitive stress. The relationship between cognitive stress and asthma was assessed at two time points: a time of normal activity (low stress visit) and again at a time of cognitive stress during examinations (high stress visit). Assessment of the subjects' perceived anxiety was done at both time points using validated tools.

\section{Methods}

Study Design

The study was approved by the Health Research Ethics Board at the University of Alberta, issue number 5240 (legacy file). A two-point crossover study design (random order) was used (Table 1). The study was advertised by posters and handbills throughout the University of Alberta. No financial compensation was provided to the subjects as it was felt that this might skew the types of participants responding to this study (recruitment bias).

Subjects were interviewed by telephone to determine whether they were eligible for the screening visit. University students (over age 18) who had a diagnosis of mild asthma, were clinically stable at baseline evaluation (as determined by an asthma specialist), and were hyper-responsive to methacholine challenge, a bronchoprovocative agent that stimulates airway narrowing, during the screening visit were included. Patients using inhaled steroids were included if their steroid dose remained stable during the course of the study. Pregnant/lactating women, smokers, and those with a significant medical condition that was felt to interfere with the study were excluded. Subjects with major psychiatric disorders (DSM-IV Axis 1 disorders) were excluded from the sample on the basis of the Mini International Neuropsychiatric Interview (MINI) screen (Sheehan et al., 1998). If a subject had an asthma exacerbation or an upper/lower airway infection at the time of any visit, the visit was delayed or rescheduled for at least four weeks following resolution of symptoms, to ensure recovery and stable clinical parameters related to the study.

Clinical and Laboratory Evaluation of the Subjects

Clinical review of cognitive stress and asthma symptoms was performed by an asthma specialist 
during all three visits (Table 1). Subjects had their low stress visit (LSV) at least fourteen days prior to examinations, by following the protocol similar to crossover allergy studies (Bizikova, 2016). Their high stress visit (HSV) was scheduled 24 hours prior to a scheduled exam to elicit a high stress experience without affecting academic performance of our participants and to minimize subject dropout. Subjects also had a methacholine challenge, spirometry, and a sputum induction performed at screening, LSV, and HSV visits. Urine cortisol levels were measured from eighthour urine samples at both the LSV and HSV.

Spirometry was performed using standards set by the American Thoracic Society (American Thoracic Society Statement, 1995) using a spirometer (Viasys Encore system). Spirometry was performed at baseline, after each dose of methacholine, and post-methacholine challenge using a calibrated rolling seal spirometer (Sensormedics 22). During spirometry, the patient breathes into and rapidly out of a calibrator (Johns et al., 2008). Methacholine challenge was performed using standardized techniques (American Thoracic Statement, 2000; Cockcroft, 1985) to evaluate bronchial hyper-responsiveness at each visit. Participants began the challenge by breathing in a low dose of methacholine followed by immediate assessment of the forced expiration measured over one second $\left(\mathrm{FEV}_{1}\right)$ with spirometry afterwards (John et al., 2008). Doubling doses of Provocholine ${ }^{\circledR}$ stock (Methapharm) were given to determine the provocative dose causing a $20 \%$ fall in FEV 1 from baseline $\left(\mathrm{PC}_{20}\right)$. Low $\mathrm{PC}_{20}\left(\mathrm{PC}_{20}\right.$ $<16 \mathrm{mg} / \mathrm{mL}$ ) indicates that bronchoconstriction is attained at lower doses of provocation and deemed a more reactive airway. In patients without asthma, $\mathrm{PC}_{20}$ is greater than $16 \mathrm{mg} / \mathrm{mL}$.

Allergen skin testing to characterize atopic status was performed at the time of screening using a standardized bank of allergens and appropriate positive and negative controls (Omega Laboratories). The allergens included pollen, mold, animal dander, and house dust mite extracts. Participants with positive allergen skin testing results were deemed atopic.

Table 1: Study design

\begin{tabular}{|l|l|l|l|}
\hline Tests/Questionnaires & Screening Visit & Low Stress Visit & High Stress Visit \\
\hline Clinical review/exam & $\mathrm{X}$ & $\mathrm{X}$ & $\mathrm{X}$ \\
\hline $\begin{array}{l}\text { Spirometry/ FEV } \\
\text { reference }\end{array}$ & $\mathrm{X}$ & $\mathrm{X}$ & $\mathrm{X}$ \\
\hline $\begin{array}{l}\text { Methacholine Challenge/ } \\
\mathrm{PC}_{20}\end{array}$ & $\mathrm{X}$ & $\mathrm{X}$ & $\mathrm{X}$ \\
\hline Sputum Induction & $\mathrm{X}$ & $\mathrm{X}$ & $\mathrm{X}$ \\
\hline MINI Screen & $\mathrm{X}$ & & \\
\hline Allergen Skin Testing & $\mathrm{X}$ & & \\
\hline Urine Cortisol (8 hrs) & & $\mathrm{X}$ & $\mathrm{X}$ \\
\hline Perceived Stress Scale & & $\mathrm{X}$ & $\mathrm{X}$ \\
\hline MASQ (Total) & & $\mathrm{X}$ & $\mathrm{X}$ \\
\hline MASQ (General Distress) & & $\mathrm{X}$ & $\mathrm{X}$ \\
\hline $\begin{array}{l}\text { EQ-5D Health Question- } \\
\text { naire }\end{array}$ & & $\mathrm{X}$ & $\mathrm{X}$ \\
\hline AQLQ (Overall Scores) & & $\mathrm{X}$ & $\mathrm{X}$ \\
\hline
\end{tabular}

Tests/questionnaires done at each visit are represented by an X. 
Questionnaire Administration

At the LSV and HSV, subjects were administered four questionnaires by the research associate: general (EuroQol-5D), disease-specific Asthma Quality of Life Questionnaires (AQLQ), Mood and Anxiety Syndrome Questionnaire (MASQ), and Perceived Stress Scale (PSS).

The PSS is a validated tool, sensitive to examination stress and was used to quantify stress levels in participating individuals (Cohen et al., 1988; Chiu et al., 2003; Garg et al., 2001). The MASQ is a series of 77 questions divided into three subsections (general distress, symptoms specific to depression and symptoms specific to anxiety)(Watson et al., 1995a). The MASQ, which discriminates between depressive anhedonia, an inability to feel pleasure, and somatic anxiety (Watson et al., 1995a; Watson et al., 1995b), was used to rate symptoms in the week prior to each test. The AQLQ is a disease-specific quality of life measure for asthma that has been validated (Juniper et al., 1999). The AQLQ is a series of 32 questions within four domains (symptoms, activity limitations, emotional function and environmental stimuli) which are assessed on a seven-point scale with 1 indicating severely impaired and 7 indicating not impaired at all (American Thoracic Society, 2017). Mean scores are assessed per domain and overall for the AQLQ (American Thoracic Society, 2017). Quality of life is important to evaluate in asthma, but does not always reflect disease severity. Reduced quality of life in the asthma population may be accounted for by a combination of many factors, including disease severity and stress. Conditions other than the disease under evaluation may contribute to reduced quality of life, so a separate tool to assess overall quality of life is required in conjunction with the above. The EQ-5D is a validated measure of general quality of life (EuroQol group, 1990) that has been used for assessing quality of life in various diseases, including asthma (Chen et al., 2007; McTaggert-Cown et al., 2008; Szende et al., 2009).
Statistical Analysis

Data are shown as mean values \pm standard error of the mean (SEM). For methacholine challenge results the geometric mean is shown. Paired t-test was used for data analysis.

\section{Results}

\section{Screening}

Thirty-eight people were interviewed and twentytwo were brought in for a screening visit. The majority of subjects interviewed by telephone and who did not come for a screening visit declined to participate because of the time commitment or the lack of financial compensation. Of the twenty-two subjects that attended the screening visit (Table 2$)$, eight (36.4\%) failed the MINI screen for reasons of generalized or social anxiety disorder, depressive or manic episodes, and alcohol abuse (four subjects failed for more than one of these reasons). Eighty percent of participants who completed the study were taking inhaled steroids at the time of the study. Two subjects did not have current asthma. One subject was no longer a student so could not meet the criteria of exam stress. Five subjects dropped out before completing the study due to the time commitment. Five subjects completed the study.

\section{Study Subjects}

The demographics of the five subjects who completed the study are shown in Table 3 and the asthma and stress data from these subjects is summarized in. Of these five subjects, three were females and two were males, four were atopic and one was non-atopic, as measured by allergen skin testing (Table 2). The mean age was 28 years. Four subjects were on low dose inhaled corticosteroids during the study period. 
Table 2: Baseline characteristics of in-person screened subjects that did not participate in the study

\begin{tabular}{|c|c|c|c|c|}
\hline Biological sex & Years & Atopic Status & Screen FEV ${ }_{1} \%$ ref. & Screen $\mathrm{PC}_{20} \mathrm{mg} / \mathrm{mL}$ \\
\hline \multicolumn{5}{|c|}{ SUBJECTS WHO WITHDREW BEFORE COMPLETION OF STUDY } \\
\hline $\mathrm{F}$ & 22 & $N D^{*}$ & 67 & ND \\
\hline M & 20 & ND & 84 & ND \\
\hline $\mathrm{F}$ & 23 & + & 104 & 0.302 \\
\hline $\mathrm{F}$ & 41 & - & 92 & 5.64 \\
\hline \multirow[t]{2}{*}{$\mathrm{F}$} & 21 & + & 100 & 1.69 \\
\hline & Mean $=25.4$ & & Mean $=89.40$ & $\begin{array}{l}\text { Geometric } \\
\text { Mean }=1.42\end{array}$ \\
\hline \multicolumn{5}{|c|}{ SUBJECTS WHO DID NOT MEET INCLUSION CRITERIA } \\
\hline M & 25 & + & 83 & ND \\
\hline$M$ & 21 & + & 79 & 2.71 \\
\hline M & 26 & + & 92 & $>16$ \\
\hline \multirow[t]{2}{*}{ M } & 29 & ND & 99 & $>16$ \\
\hline & Mean $=25.2$ & & Mean $=88.25$ & $\begin{array}{l}\text { Geometric } \\
\text { Mean }=8.853\end{array}$ \\
\hline \multicolumn{5}{|c|}{ SUBJECTS WHO FAILED MINI SCREEN } \\
\hline $\mathrm{F}$ & 18 & - & 120 & 5.12 \\
\hline M & 41 & ND & ND & ND \\
\hline $\mathrm{F}$ & 20 & ND & ND & ND \\
\hline $\mathrm{F}$ & 26 & ND & 114 & ND \\
\hline $\mathrm{F}$ & 28 & + & 105 & 0.067 \\
\hline M & 22 & + & 99 & ND \\
\hline M & 52 & ND & 104 & ND \\
\hline \multirow[t]{2}{*}{ M } & 21 & ND & 87 & ND \\
\hline & Mean $=28.5$ & & Mean $=104.8$ & $\begin{array}{l}\text { Geometric } \\
\text { Mean }=0.59\end{array}$ \\
\hline
\end{tabular}

$\mathrm{ND}=$ No data; $\mathrm{F}$ = female; $\mathrm{M}=$ male;

$\mathrm{FEV}_{1}=$ the forced expiratory volume in one second as measured by spirometry

$\mathrm{PC}_{20}=$ the dosage of methacholine required to reduce $\mathrm{FEV}_{1}$ by $20 \%$

Positive atopy status = positive allergen testing;

$\mp$ Geometric mean log base 10

Table 3: Demographics of subjects who completed study

\begin{tabular}{|l|l|l|l|l|l|l|}
\hline Age & Gender & $\begin{array}{l}\text { Atopic } \\
\text { Status }\end{array}$ & $\begin{array}{l}\text { Reporting worsening } \\
\text { of asthma with stress }\end{array}$ & $\begin{array}{l}\text { Screen } \\
\text { FEV\% ref }\end{array}$ & $\begin{array}{l}\text { Use of low dose In- } \\
\text { haled Corticosteroids }\end{array}$ & PC $_{20}($ Baseline $)$ \\
\hline 39 & F & + & no & 119 & None & 7.87 \\
\hline 19 & M & - & no & 121 & Fluticasone & 13.4 \\
\hline 21 & F & + & no & 72 & Fluticasone & 0.34 \\
\hline 37 & F & + & yes & 105 & Beclomethasone & 0.042 \\
\hline 24 & M & + & yes & 99 & Fluticasone & 0.048 \\
\hline
\end{tabular}

$F=$ female; $M=$ male

$\mathrm{FEV}_{1}=$ the forced expiratory volume in one second as measured by spirometry

$\mathrm{PC}_{20}=$ dose of methacholine required to decrease $\mathrm{FEV}$, by $20 \%$ 
Table 4: Summary of data from subjects who completed study

\begin{tabular}{|l|l|l|l|l|}
\hline & Screening & LSV & HSV & $\begin{array}{l}\text {-value (between } \\
\text { LSV and HSV) }\end{array}$ \\
\hline $\begin{array}{l}\text { FEV } \\
(\text { SEM })\end{array}$ & $103.2(19.75)^{\star}$ & $104.0(15.65)$ & $108.0(14.46)$ & 0.53 \\
\hline $\begin{array}{l}\mathrm{PC}_{20}(\mathrm{n}=5) \text { Geomet- } \\
\text { ric mean }\end{array}$ & 0.5913 & 1.012 & 1.574 & 0.98 \\
\hline $\begin{array}{l}\text { AQLQ (Overall } \\
\text { Scores) }(\mathrm{n}=5)\end{array}$ & Not applicable & $6.366(0.6063)$ & $6.456(0.2324)$ & 0.65 \\
\hline $\begin{array}{l}\text { EQ-5D Health Ques- } \\
\text { tionnaire }(\mathrm{n}=5)\end{array}$ & Not applicable & $8.50(0.6042)$ & $8.10(0.8689)$ & 0.27 \\
\hline $\begin{array}{l}\text { Perceived Stress } \\
\text { Scale }(\mathrm{n}=5)\end{array}$ & Not applicable & $26.60(5.225)$ & $31.40(6.580)$ & 0.26 \\
\hline $\begin{array}{l}\text { MASQ (Total) } \\
(\mathrm{n}=5)\end{array}$ & Not applicable & $92.60(21.71)$ & $97.0(24.34)$ & 0.31 \\
\hline $\begin{array}{l}\text { MASQ (General } \\
\text { Distress) }(\mathrm{n}=5)\end{array}$ & Not applicable & $26.20(5.805)$ & $30.0(7.906)$ & 0.08 \\
\hline $\begin{array}{l}\text { Urine Cortisol (total } \\
8 \text { hours) }(\mathrm{n}=4)\end{array}$ & Not applicable & $120.3(27.22)$ & $73.25(64.16)$ & 0.20 \\
\hline
\end{tabular}

$\mathrm{FEV}_{1}=$ the forced expiratory volume in one second as measured by spirometry

LSV = low stress visit; HSV = high stress visit

$\mathrm{PC}_{20}=$ dose of methacholine required to decrease $\mathrm{FEV}_{1}$ by $20 \%$

* Data shown as: Mean (standard deviation)

9 Geometric mean of methacholine challenge results $\left(\mathrm{PC}_{20}\right)$ - log based 10

₹ Number of subjects who completed test on each visit successfully

$€$ Calculated using paired t-tests

\section{Physiological Measures}

Two of the five subjects had a history of stressrelated worsening of their asthma. The geometric mean $\mathrm{PC}_{20}$ (at screening visit) for the group that completed the study was $0.5913 \mathrm{mg} / \mathrm{mL}$.

\section{Psychosocial Measures}

Subjects who completed the study showed no significant change in the PSS between the LSV and HSV $(p=0.5078)$. Similarly, no change was noted in total scores for the MASQ $(p=0.3057)$. There was a trend towards increase in the General Distress subsection of this questionnaire $(p=0.0795)$, although this also did not reach statistical significance (Table 4).

\section{Quality of Life Measures}

No significant change was noted in the general quality of life questionnaire (EQ5D) evaluations or disease specific AQLQ (AQLQ Overall: $\quad \mathrm{p}=0.6460$, Symptoms: $p=0.9331$ ) between the LSV and HSV (Table 4).

\section{Airway Physiology}

No significant change was noted in lung function (FEV $\left.{ }_{1} \%\right)$ between LSV and HSV ( $\left.p=0.5275\right)$ (Table 4). The results of the methacholine challenge $\left(\mathrm{PC}_{20}\right)$ also showed no significant difference $(p=0.9813)$ in airway hyper-responsiveness between low and high stress visits (Figure 1). 


\section{Methacholine Challenge}

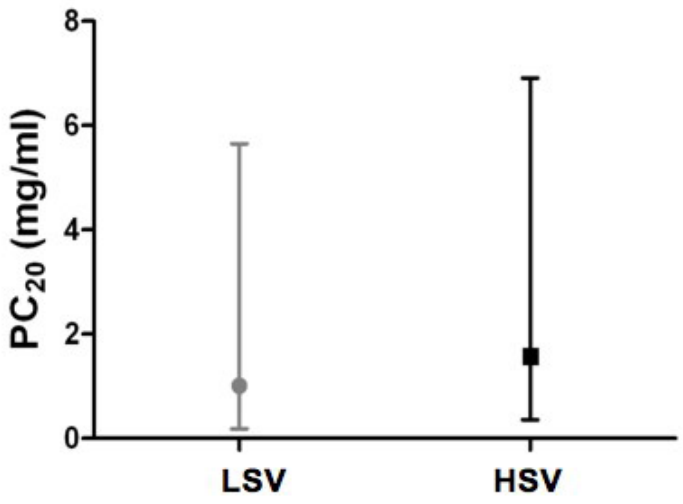

Urinary Cortisol

No significant difference was noted between the LSV and HSV in either concentrated $(\mathrm{g} / \mathrm{L})$ or total $(\mu \mathrm{g})$ urinary cortisol levels when testing eight-hour urine samples received at each visit $(p=0.3012$ and $p=0.2017$ respectively)(Table 4).

\section{Discussion}

Underlying psychiatric diagnoses (as per the DSM-IV, the current edition of the DSM at the time of recruitment) were prevalent in this "healthy asthma" population recruited for our study. The recruitment resulted in the exclusion of a large number of subjects (36\%) - similar to numbers quoted in other studies (Harrison, 1998; Krommydas et al., 2004; Strunk et al., 2016). In the subjects who completed the study, no significant physiological or inflammatory worsening of asthma was noted during the putative HSV. We did not notice any significant change in quality of life measures. The main limitation of the study, in addition to the small number of subjects, was that these individuals did not exhibit elevated stress levels during the examination period as assessed by the MASQ and PSS scales. This may have been in part related to the underlying use of inhaled corticosteroids (ICS). Current hypotheses focus on the role of eosinophils a type of white blood cell, as a mechanism targeted
Figure 1: Methacholine Challenge

Data points are geometric means with $95 \%$ confidence interval (log base 10) for the $\mathrm{PC}_{20}$ (dose of methacholine required to drop $\mathrm{FEV}_{1}$ by $20 \%$ ) of the five subjects who completed the study.

LSV = Low Stress Visit HSV $=$ High Stress Visit

by inhaled corticosteroids, implicated in asthma and stress (Black, 2002; Chen et al., 2007). Since our subjects did not have increased stress levels during what we expected to be an HSV, it is difficult to draw any conclusions about the effects of stress on allergic airway inflammation. However, the limitations of the study outline the necessity of identifying psychosocial factors and appreciating the individual reactions to stress, which may have effects on physiological processes in allergic diseases.

As psychiatric pathology is prevalent in the asthma population, it is important in future studies to screen prior, as it may be a confounding variable to the effect of stress on airway disease. Different scales may be important with specific research questions involving the relationship between stress and asthma; hence careful involvement with clinical professionals working with these patients is important to evaluate the relevance of psychiatric comorbidities in asthma. Indeed, based on the high prevalence of psychiatric comorbidity, asthma specialists at the University of Alberta have started formal psychiatric comorbidity evaluation of clinical asthma patients in clinic.

As mentioned, because subjects did not seem "stressed" during the HSV, the individual stress phenotype, the type of stress assessed, and duration of stress (chronic, acute, situational) 
may have varied between subjects but may be more important as further studies are developed to look at this issue. Although our study is small, it underscores the importance of objective measures of stress, such as the inflammatory markers of stress, for studies on the effects of stress on asthma or other inflammatory conditions.

We postulated that there would be decreases in $F E V_{1}$ and $P_{20}$ associated with increased stress, with more notable changes in quality of life measures. We also expected that physiologic changes and quality of life measures would correlate with increased cognitive stress, along with airway inflammation. Unfortunately, with no changes in stress levels, these hypothesis could not be rigorously tested.

Out of the five patients participating in the study only two reported a history of worsening of respiratory symptoms during periods of stress. It is interesting that both these patients were atopic and had severe airway hyperreactivity $\left(\mathrm{PC}_{20}\right.$ of 0.042 and $0.048 \mathrm{mg} /$ $\mathrm{mL}$ ). Severe airway hyper-responsiveness may predispose an individual to increased symptoms during a stressful period (Rod et al., 2012).

The low sample size reflects study interruption, which could increase the likelihood of type 2 error, noting no significant difference when a difference exists (Kadam et al., 2016). The low study completion $(n=5)$ related to the large number of inclusion and exclusion criteria and inflexibility in scheduling the HSV (within 24 hours of their exam). For future studies, incentivizing completion of follow-up appointments, sending reminder emails about upcoming appointments and making follow-up appointments less complex to reduce the time commitment may increase the subject pool (Ngune et al., 2012; Kadam et al., 2016).

We do believe this information is still important to share given the implications for future study designs in asthma clinical trials. From this data and review of the literature, it is important to use an interdisciplinary approach to management of asthma including family physicians, allied health, psychiatry and pulmonary medicine. Identification of risk factors, medication management and adjustments by stress and regular followup will promote improved functioning and quality of life among individuals with asthma

Studies on asthma should incorporate measures of psychiatric comorbidity to better elucidate factors related to loss of asthma control

\section{Acknowledgments}

This study was funded in part by the Alberta MSI Foundation and the Department of Medicine, University of Alberta

\section{Conflicts of Interest}

The authors declare that there is no conflict of interest in the publication of this article. 


\section{References}

American Academy of Allergy Asthma \& Immunology. (2018). Atopy. Retrieved from https://www.aaaai. org/conditions-and-treatments/conditions-dictionary/atopy

American Thoracic Society (2017). Asthma quality of life questionnaire (AQLQ). Retrieved from http:// www.thoracic.org/members/assemblies/assemblies/srn/questionaires/aqlq.php

American Thoracic Society Statement (1995). Standardization of Spirometry. 1994 Update. American Journal of Respiratory Critical Care Medicine, 152, 1107-1136. https://doi.org/10.1164/ ajrccm.152.3.7663792

American Thoracic Society Statement (2000). Guidelines for methacholine and exercise challenge testing - 1999. American Journal of Respiratory Critical Care Medicine, 161, 309-29. https://doi. org/10.1164/ajrccm.161.1.ats11-99

Becker A., Lemiere, C., Berube, D., Boulet, L.P., Ducharme, F.M., FitzGerald M., \& Kosevi T. (2005). Summary of recommendations from the Canadian asthma consensus guidelines, 2003. Canadian Medical Association Journal, 173, S3-11.

Bizikova, P., \& Olivry, T. (2016). A randomized, double-blinded crossover trial testing the benefit of two hydrolysed poultry-based commercial diets for dogs with spontaneous pruritic chicken allergy. Veterinarian Dermatology, 27, 289-e70. https://doi.org/10.1111/vde.12302

Black, P.H. (2002). Stress and the inflammatory response: A review of neurogenic inflammation. Brain Behavior and Immunology, 16, 622-53. https://doi.org/10.1016/S0889-1591(02)00021-1

Chen, H., Gould, M.K., Blane, P.D., Miller, D.P., Kamath, T.V., ... TENOR Study Group. (2007). Asthma control, severity, and quality of life: quantifying the effect of uncontrolled disease. Journal of Allergy Clinical Immunology, 120(20), 396-402. https://doi.org/10.1016/j.jaci.2007.04.040

Chen, E., \& Miller, G. (2007). Stress and Inflammation in Exacerbations of Asthma. Brain Behavior and Immunology, 21(8), 993-999. https://doi.org/10.1016/j.bbi.2007.03.009

Chiu, A., Chon, S.Y., \& Kimball, A.B. (2003). The response of skin disease to stress: changes in the severity of acne vulgaris as affected by examination stress. Archives of Dermatology, 139, 897-900. https://doi.org/10.1001/archderm.139.7.897

Christensen, C.W., Isenberg, J.C., Mullin, L.L., Carpentier, M.Y., \& Almstrom, C. (2008). Objective vs. subjective ratings of asthma severity: Differential predictors of illness uncertainty and psychological distress in college students with asthma. Children's Health Care, 37, 183-195. https://doi.org/10.1080/02739610802151514

Cockcroft, D.M. (1985). Measure of airway responsiveness to inhaled histamine or methacholine; method of continuous aerosol generation and tidal breathing inhalation. In F.E. Hargreave \& A.J. Woolcock (Eds.), Airway responsiveness: measurement and interpretation (pp. 22-28). Mississauga: Astra Pharmaceuticals Canada Ltd.

Cohen, S., Kamarack, T., \& Memelstein, R. (1988). A global measure of perceived stress. Journal of Health and Social Behavior, 24, 385-396. http://psycnet.apa.org/doi/10.2307/2136404

Davis, T.M., Ross, C.J., \& MacDonald, G.F.(2002). Screening and assessing adult asthmatics for anxiety disorders. Clinical Nursing Research, 11, 173-89. https://doi.org/10.1177/105477380201100206

Dunton, G., Dzubur, E., Li, M., Huh, J., Intille, S., \& McConnell, R. (2016). Momentary assessment of psychosocial stressors, context and asthma symptoms in Hispanic adolescents. Behavior Modification, 40(1-2), 257-280. https://doi.org/10.1177/0145445515608145

Garg, A., Chren, M.M., Sands, L.P., Matsui, M.S., Mareunus, K.D., ... Elias, P.M. (2001). Psychological stress perturbs epidermal permeability barrier homeostasis: implications for the pathogenesis 
of stress-associated skin disorders. Archives of Dermatology, 137, 53-9. https://doi.org/10.1001/ archderm.137.1.53

Global Initiative for Asthma (GINA) (2016). Retrieved from http://www.ginasthma.com/ Goodwin, R.D., \& Pine, D.S. (2002). Respiratory disease and panic attacks among adults in the United States. Chest, 122, 645-50. https://doi.org/10.1378/chest.122.2.645

Harrison, B.D.W. (1998). Psychosocial aspects of asthma in adults. Thorax, 53, 519-25. http://dx.doi. org/10.1136/thx.53.6.519

Isenberg, S.A., Lehrer, P.M., \& Hochron, S. (1992). The effects of suggestion and emotional arousal on pulmonary function in asthma: a review and a hypothesis regarding vagal mediation. Psychosomatic Medicine, 54, 192-216.

Johns, D.P., \& Pierce, R. (2008). The measurement and interpretation of ventilator function in clinical practice. Melbourne, VIC: National Asthma Council.

Juniper, E.F., Buist, A.S., Cox, F.M., Ferrie, P.J., \& King, D.R. (1999). Validation of a standardized version of the asthma quality of life questionnaire. Chest, 115, 1265-70. https://doi.org/10.1378/ chest.115.5.1265

Kadam, R.A., Borde, S.U., Madas, S.A., Salvi, S.S., \& Limaye, S.S. (2016). Challenge in recruitment and retention of clinical trial subjects. Perspectives in Clinical Research, 7, 137-143. https://doi. org/10.4103/2229-3485.184820

Krommydas, G.C., Gourgoulianis, K.I., Angelopoulos, N.V., Kotrotsiou, E., Raftopoulos, V., \& Molyvdas, P.A. (2004). Depression and pulmonary function in outpatients with asthma. Respiratory Medicine, 98, 220-24. https://doi.org/10.1016/j.rmed.2003.09.018

Lehrer, P.M., Isenberg, S., \& Hochron, S.M. (1993). Asthma and emotion: a review. Journal of Asthma, 30, 5-21. https://doi.org/10.3109/02770909309066375

Liu, L.Y., Coe, C.L., Swenson, C.A., Kelly, E.A., Kita, H., \& Busse, W.W. (2002). School examinations enhance airway inflammation to antigen challenge. American Journal of Respiratory Critical Care Medicine, 165, 1062-1067. https://doi.org/10.1164/ajrccm.165.8.2109065

Lu Y., Ho R., Lim T.K., Kuan W.S., Goh D.Y. Mahadevan M., ... van Bever H.P. (2014). Psychiatric comorbidities in Asian adolescent asthma patients and the contributions of neuroticism and perceived stress. Journal of Adolescent Health, 55, 267-275. https://doi.org/10.1016/j. jadohealth.2014.01.007

McTaggert-Cown, H.M., Marra, C.A., Yang, Y., Brazier, J.E., Kopec, J.A., ... Lynd, L.D. (2008). The validity of generic and condition-specific preference-based instruments: the ability to discriminate asthma control status. Quality of Life Research, 17(3), 453-62.

https://doi.org/10.1007/s11136-008-9309-6

Ngune, I., Jiwa, M., Dadich, A., Lotriet, J., Sriram, D.(2012). Effective recruitment strategies in primary care research: a systematic review. Quality in Primary Care, 20, 115-123.

Osler W. (1892). The principles and practice of medicine. Edinburgh, NY: Pentland.

Rod, N.H., Kristensen, T.S., Lange, P., Prescott, E., \& Diderichsen, F. (2012). Perceived stress and risk of adult-onset asthma and other atopic disorders: A longitudinal cohort study. European Journal of Allergy and Clinical Immunology, 67, 1408-1414. https://doi.org/10.1111/j.13989995.2012.02882.x

Rosner F. (1981). Moses Maimonides' treatise on asthma. Thorax, 36, 245-51. http://dx.doi.org/10.1136/ thx.36.4.245 
Sears, M.R., Rea, H.H., Fenwick J., Beaglehole R., Gillies A.J., ... Sutherland, D.C. (1986). Deaths from asthma in New Zealand. Archives of Disease in Childhood, 61, 6-10.

Selye, H. (1970). The evolution of the stress concept. Stress and cardiovascular disease. American Journal of Cardiology, 26, 289-99.

Sheehan, D.V., Lecrubier, Y., Sheehan, K.H., Amorim, P., Janavas, J., ... Dunbar, G.C. (1998). The MiniInternational Neuropsychiatric Interview (M.I.N.I.): the development and validation of a structured diagnostic psychiatric interview for DSM-IV and ICD-10. Journal of Clinical Psychiatry, 59, 22-33.

Smyth, J.M., Stone, A.A., Hurewitz, A., \& Kaeli A. (1999). Effects of writing about stressful experiences on symptom reduction in patients with asthma or rheumatoid arthritis: a randomized trial. Journal of the American Medical Association, 281, 1304-1309. http://psycnet.apa.org/doi/10.1001/ jama.281.14.1304

Statistics Canada, Health in Canada (2017, March 22). Retrieved from http://www.statcan.gc.ca/pub/82-625-x/2017001/article/14762-eng.htm

Strunk, R.C., Mrazek, D.A., Fuhrmann, G.S., \& LaBrecque, J.F. (1985). Physiologic and psychological characteristics associated with deaths due to asthma in childhood: a case-controlled study. Journal of the American Medical Association, 254, 1193-8.

Sundbom, F., Malinovschi, A., Lindberg, E., Alving, K., \& Janson C. (2016). Effects of poor asthma control, insomnia, anxiety and depression on quality of life in young asthmatics. Journal of Asthma, 53(4), 398-403. https://doi.org/10.3109/02770903.2015.1126846

Szende, A., Leidy, N.K., Stahl, E., \& Svensson, K. (2009). Estimating health utilities in patients with asthma and COPD: evidence on the performance of EQ-5D and SF-6D. Quality Life Research, 18(2), 26772. https://doi.org/10.1007/s11136-008-9429-z

The EuroQol group. (1990). EuroQol -a new facility for the measurement of health-related quality of life. Health Policy, 16, 199-208.

Trueba, A.F., Simon, E., Auchus, R.J., \& Ritz, T. (2016). Cortisol response to acute stress in asthma: Moderation by depressive mood. Physiology \& Behavior, 159, 20-26. https://doi. org/10.1016/j.physbeh.2016.03.005

Van Den Toorn, L.M., Overbeek, S.E., De Jongste, J.C., Leman, K., Hoogsteden, H.C. \& Prins, J.B. (2001). Airway inflammation is present during clinical remission of atopic asthmatics. American Journal of Respiratory Critical Care Medicine, 164, 2107-13. https://doi.org/10.1164/ ajrccm.164.11.2006165

Vila, G., Nollet-Clemencon, C., Vera, M., Robert, J.J., de Blic, J., Jouvent, R., ... Scheinmann, P. (1999). Prevalence of DSM-IV disorders in children and adolescents with asthma versus diabetes. Canadian Journal of Psychiatry, 44, 62-69. https://doi.org/10.1177/070674379904400604

Watson, D., Clark, L.A., Weber, K., Assenheimer, J.S., Strauss M.E., \& McCormick R.A. (1995a). Testing a tripartite model: II. Exploring the symptom structure of anxiety and depression in student, adult, and patient samples. Journal of Abnormal Psychology, 104, 15-25. http://psycnet.apa.org/ doi/10.1037/0021-843X.104.1.15

Watson, D., Weber, K., Assenheimer, J.S., Clark, L.A., Strauss, M.E., \& McCormick, R.A. (1995b). Testing a tripartite model: I. Evaluating the convergent and discriminant validity of anxiety and depression symptom scales. Journal of Abnormal Psychology, 104, 3-14 http://psycnet.apa.org/ doi/10.1037/0021-843X.104.1.3 
World Health Organization (2018). Constitution of WHO: Principles. Retrieved from http://www.who.int/ about/mission/en/

Wright, R.J, Rodriguez M., \& Cohen S. (1998). Review of psychosocial stress and asthma: an integrated biopsychosocial approach. Thorax, 53, 1066-1074. http://dx.doi.org/10.1136/ thx.53.12.1066doi/10.1037/0021-843X.104.1.15 